\title{
Fermín Salvochea en vísperas de "La Gloriosa»: aproximación ideológica
}

\section{JOSÉ MARCHENA DOMÍNGUEZ Universidad de Cádiz}

La subida a la presidencia de Narváez en julio de 1866, a ritmo de Estado de Excepción y de Real Orden que suspendía las garantías constitucionales, inició prácticamente el último capítulo del accidentadó reinado de Isabel II.

La insurrección definitiva estaba próxima y, con ella, el fin de una larga serie de gabinetes moderados, exceptuando el bienio progresista y los gobiernos de O'Donnell, que no pudieron solucionar los graves problemás económicos y sociales que el país venía arrastrando desde la caída del antiguo régimen.

Varios fueron los grupos y sectores de población que cooperaron en la consumación revolucionaria; uno de ellos, formado por teóricos y activistas escindidos del bando Progresista desde 1849, que reivindicaron nuevas ideas de tintes republicanos y socialistas premarxistas; en Cádiz, el Partido Demócrata -así se denominaron- comenzó sus trabajos en la década de los sesenta, fecha en la que encontramos inserto a uno de sus más activos militantes: Fermín Salvochea Alvarez (1).

De familia comerciante acomodada, tuvo a los quince años la oportunidad de estudiar en Inglaterra, so pretexto de su formación comercial, algunos teóricos como Paine, Robert Owen o Charles Bredlow. Se-

(1) Para consultar los estudios acerca de Fermín Salvochea, v.: MISTRAL, E., Vida revolucionaria de Fermín Salvochea. Valencia, 1937; ROCKER, R., Fermín Salvochea: precursores de la libertad. Toulouse, 1945; VALLINA, P., Crónica de un revolucionario con trazos de la vida de Fermín Salvochea. París, 1958; MORENO, I., Aproximación histórica a Fermín Salvochea. Cádiz, 1982; PUELLES, F., Fermín Salvochea, República y Anarquismo. Sevilla, 1984, y BREY, G., y otros. Fermin Salvochea. Un anarchiste entre la legend et l'histoire, Saint-Denis, 1987. 
gún Vallina, de estos tres teóricos tomó Salvochea la base de su doctrina ideológica; del primero, su concepción internacionalista, y de los dos restantes, a los que conoció personalmente, las ideas comunistas y ateas respectivamente.

Su regreso a Cádiz le posibilitó contactar con el grupo Demócrata Gaditano en 1863, coincidiendo con su despegue definitivo en las principales ciudades, tanto a nivel organizativo como propagandístico. Efectivamente Salvochea pasó a formar parte del Comité Democrático de Cádiz, en un momento en que el partido se planteaba el retraimiento electoral, y en el que Roque Barcia atacaba desde el órgano gaditano $E l$ Demócrata Andaluz las doctrinas del Neocatolicismo, en uno de los momentos más brillantes de la prensa demócrata gaditana.

Sin embargo, los sucesos acaecidos por el pronunciamiento en el Cuartel de San Gil, la implicación de los sectores políticos más radicales y la Real Orden antes referida, supuso la emigración de importantes elementos progresistas y demócratas a Francia y Portugal, donde siguieron con los preparativos revolucionarios.

Entretanto, el grupo revolucionario gaditano desarrollaba en la clandestinidad la organización de un objetivo que ya se veía cercano, gracias al acercamiento entre los sectores populares y los políticos antiisabelinos por un lado, y a los generales progresistas y unionistas junto a gran parte de las guarniciones militares de Cádiz, San Fernando y Ceuta, por otro (2).

Si bien los trabajos y preparativos eran desempeñados personalmente por los activistas, que exponían continuamente sus personas con viajes a Ceuta y la provincia gaditana, la prensa también fue perseguida por vía legal, lo que no desmereció el talante valiente y luchador de los "supervivientes", que en palabras de Eduardo Benot "desarrollan como propaganda activa y eficaz /.../ sin cesar de repartir el credo democrático". Así, la escasa prensa con participantes demócratas, o bien era clandestina, o bien se escudaban bajo artículos literarios sin compromiso ideológico, la mayoría de las veces bajo seudónimo o iniciales.

En 1867, y bajo este clima, nacía el "periódico de intereses materiales, ciencias, literatura, costumbres y teatros» Revista Gaditana, dirigida y editada por Víctor Caballero y Valero, siendo el único título disponible en Cádiz donde aparecen colaboradores demócratas. Figuraron, entre otros articulistas de diverso credo, los demócratas Narciso Cam-

(2) Sobre el Partido Demócrata Gaditana, v. Tesis de Licenciatura de JOSÉ MARCHENA DOMÍNGUEZ, leída en la Universidad de Cádiz, marzo de 1987. 
pillo, Ambrosio Grimaldi, Pedro Canales, José Sanz Pérez, Buenaventura: Abarzuza y Fermín Salvochea.

Fue el último sin duda el más prolijo de todos, escribiendo durante la segunda mitad de 1867 y el primer trimestre de 1868 diecisiete artículos, donde a la exquisita forma literaria se le sumaba un original y depurado matiz crítico, sin perder en ningún caso la ironía y el humor sarcástico.

El tema social es tratado por Salvochea de forma pormenorizada. Su conexión con las ideas de Owen y Cabet de un individuo bueno por naturaleza, alterado por la mala estructuración y el desequilibrio social -idea esta de tradición ilustrada-, queda plasmado en sus escritos:

«El poco ambicioso, el que se contenta con muy pequeña cosa se le llama ladrón, y la sociedad le condena: al emprendedor, al que quiere mucho y si no se lo den lo toma, se le apellida conquistador, y la sociedad le acata y venera".

Este desequilibrio, viene básicamente otorgado por el afán personal de superar y aparentar ser más que el otro, en un modelo social donde para Salvochea, no media ningún tipo de consideraciores ni prejuicios, tal que "buscando la felicidad se mataban los hombres /.../ sin pararse a reflexionar que cada cual de los combatientes la tenía en los labios". Los objetivos sinceros y válidos del hombre en sociedad se van tergiversando por la degeneración de valores; en cierta forma, la idea de Fourier de una sociedad regida por las pasiones divinas y naturales, siempre amenazada por la moral social, entroncaría en este postulado:

«Las magnéticas palabras aurora, igualdad, paz, lealtad, riqueza y felicidad /.../ han producido siempre maravillosos resultados /.../ hasta hacerle olvidar sus más sagrados deberes $/ \ldots / \mathrm{El}$ afán de lograr lo que no tenemos nos hace olvidar el bien que disfrutamos; siempre parece más colmada la mies en el campo ajeno; más abundante en leche el rebaño vecino. Deseos, inconstancia, orgullo y fanatismo...".

Es la realidad de una actitud social que a la postre para Salvochea, tendría consecuencias funestas al descubrir que, "la adulación y la hipocresía, ídolos de la fanática sociedad, querían lucir sus galas, y sus galas no eran más que harapos, si se examinaban a la luz de la verdad $\% .$. / Desgraciado del que se engañase en descorrerlo, porque ¿qué es lo que vería? ¿qué sería a los ojos de la sociedad? Un laberinto, un infiernom: (3).

(3) Revista Gaditana, 16 y 30 jul. 1867, 24 ago. 1867 y 16 ene. y 24 feb. 1868. 
Prueba de esta denuncia a la situación social, la encontramos en varios ejemplos y comparaciones simbólicas; la simple conversación entre dos ciudadanos sirve de excusa para mostrar una pincelada de este desajuste de valores:

«D. Jorge y D. Simeón son enemigos irreconciliables. El uno daría un ojo de muy buena gana por dejar ciego a su antagonista; pero la sociedad exige que al encontrarse estos bienaventurados haya aquello de "ĉuanto me alegro de verlo a V. siempre tan guapo"...".

En otros casos habla de la vida social como "un bonito viaje, y nosotros muy felices... cuando llegamos a tierra, que el mar cuesta muchas lágrimas aunque le llamen pacífico"; también llega a hablar de su propia infancia para criticar las desarcetadas motivaciones adquiridas para con la vida, o de un niño que va percibiendo los distintos templos /realidades/ de la vida y como se va desarrollando: un jardín que es un lienzo, el amor que es' lisonja; la llegada de otros más positivos, como la constancia y la amistad no evitan el ennegrecimiento por la ingratitud, lo que le obliga a huir a una llama en extinción llamada honor. Este contraste fourierista entre pasiones y moral social queda rematado por una serie de cuestiones: "¿qué queda de la vida? ¿qué queda de esos bienes que me ofrecías, seductora sociedad? Por tí he perdido la paz de mi retiro; en aras de tus ideales he sacrificado hasta mi corazón. Soñé con el amor, y me engañaste; creí en la amistad, y me vendiste; confié en tu honor, y tu honor no era más que humo ¿qué me queda que esperar, o qué me queda que padecer?».

También Salvochea encuentra tema en un teatro donde con supuestos cánones shakesperianos, el escenario es la sociedad, el público los que pagaban y los artistas quienes cobraban. En él eran previsibles cambios inesperados; "...tan pronto es uno gentil a secas, como gentil hombre; ayer rendido amante y vil seductor mañana; esclavo, gran señor y capitán de bandidos en tres escenas del mismo drama».

Dos argumentos más sirven de escenario para describir nuevos aspectos sociales: el primero, el símil de los retales, donde una vez más localizamos el concepto de la pasión fourierista, para criticar la crisis de valores en la realidad social. Así, "la vida es un vestido de Arlequín. En ella /.../ hay multitud de telas. Abundan las de menos precio y escasean las de valor. Un pedacito de inocencia /.../ otro mayor de ambición con esperanza / .../ otro pedazo de amor / .../ otro pedacito de gratitud /.../ un retazo chiquito de amistad /.../ una tirita de honradez $/ . . /$ dos deditos de justicia /.../ un pedazo grande $/ .$. / de desengaños». Del segun- 
do, una alegoría del Carnaval como exponente de las pasiones y realidades auténticas del individuo, que paradójicamente se tachan dé convencionales, frente a la cultura y a la moral social:

«En el baile de máscaras, en el llamado farsa, la sociedad no ejerce poder alguno sobre los asociados: un pedazo de cartón ha reconquistado a la humanidad su libertad perdida /.../ cada máscara es un cómico que harto de fingir un año entero, quiere decir en libertad lo que su corazón siente $/ . . . /$ ¡Y a esto se llama farsa! $; Y$ a la que dura todo el año se le dan pomposos nombres de cultura y de ilustración! /.../ se llama farsa al Carnaval porque en él no tiene entrada la lisonja, ni llaman la atención los títulos /.../ sólo en Cárnaval nos es permitido ver» (4).

Tras estos planteamientos teóricos, Salvochea penetra con sus artículos en el tejido social que va desgranando todos aquellos detalles que centran su revisionismo.

Sobre el tema de la moda, lo aprovecha para ironizar en una de sus vertientes a la vida büruesa gaditana, cuya predisposición para ponerse a punto del paseo - por ejemplo-, lo hacen a base de privarse de necesidades. Así, el comerciante que les ve pasar hacia la Plaza de Mina, duda que no tengan dinero para pedirle fiado.

Sin perder el sentido irónico y de humor característicos, se mofa de las exigencias del vestuario y su sentido aparentador y económico; también lo hace de otros gastos burgueses de moda, como los viajes a capitales europeas o los cambios de viviendas y mobiliarios.

Sobre el primer caso, Salvochea hace una relación de prendas con sus correspondientes comentarios:

"Una mantilla francesa de bolillos Vestido de raso con blondas y adminículos

Rvn. 3.000

Abanico de moda y por consiguiente de dos caras

Pendientes que a muchas dejan colgadas

6.000

Pañolón de China con muñequitos bordados como aquel de la ganga

Un corsé francés con todos los bigotes de una ballena

Unas enaguas de miriñaque y otras de bretaña

Pachulí, guantes, medias gallegas, botas de colom-

biano o zapatos de orillo; es igual, no han de verse

Pañuelo de estopilla olanada clarín

(4) Ibídem, 30 jul., 24 sep., 8,24 y 30 oct. 1867 y 24 fìb. 1868. 
En su lugar plantea una lista alternativa visiblemente más austera, con la consiguiente enseñanza de limitar los costes superfluos (5).

El tema de las festividades y celebraciones se empapa en esta ocasión en Salvochea, de realidades demokrausistas, al considerar al estado liberal "enfermo" y plagado de bases ideológicas que jerarquizan sus fines y funciones.

De esta forma critica el consumismo y la artificialidad de fiestas de justificación religiosa, como la Navidad, que "nos lo dice el almanaque y nuestros enemigos /.../ la miseria humana debe hacer un paréntesis para que la tierra deje de ser alguna vez valle de lágrimas /.../ época anti-económica y subversiva, a la que en vez de llamar carga a la bayoneta, da el nombre de pascuas los que cobran y ascuas los que pagan /.../ con vestir de máscara el corazón y fortalecer el espíritu con espíritu de vino, se ven hasta visiones".

Al otro lado de las celebraciones burguesas y de la misma forma, Salvochea cuestiona la filosofía y maneras de los velatorios y funerales y con ello, el ideal ante la muerte. Una actitud que para éste, sigue denotando el interés y la ambición social en modalidades como la herencia:

"¡Qué hace V. Tío! ¡salir tan de mañana en un día como hoy!

- Hombre que quieres. Me aburro en casa, y luego el día no me parece tan malo como dices.

-El Norte es malísimo, si señor, muy malo, y V. debe cuidarse.

-Si hombre pero no tanto.

- Toda precaución es poca. Si un capricho costase a V. una enfermedad... Sólo de pensarlo me horrorizo.

Lo que le horroriza al sobrino es la idea de perder la herencia".

Califica a los velatorios como "actos dramáticos», y "entreactos" a los ofrecimientos que allí se suelen dar:

«... buenas tazas de caldo y algunos tragitos de loa añejo, que a tragos se ha de pasar la vida, se da el pomposo título de tente en pie, como si una mujer y viuda por añadidura, necesitase de estimulante para tenerse en pie /.../ como las grullas».

La actitud de aparicncia y ostentación social se mantiene en el mun-

(5) Ibídem, 16 jul. 1867 y 8 feb. 1868. 
do burgués prácticamente hasta el final de la vida. Para Salvochea, la celebración de los difuntos no es sino una parte más de esa parafernalia:

"Las luces se apagan; los encargados de la pompa mundana despojan a los sepulcros de sus atavíos, y la dispersa comitiva se reúne para abandonar este lúgubre recinto. Una sola idea la condujo, la ostentación: está ya satisfecha y... se retira. La farsa de hoy ha concluido. La sociedad se divierte con los vivos, todo el año; con los muertos, el dos de noviembre".

En general, queda planteada una actitud de rechazo, ante la irrealidad de los valores sociales predominantes de una burguesía que se ahoga en su propia insulsez y que inunda con ello todo cuanto la rodea; Salvochea recapitula y cuestiona, "iqué podéis esperar de una sociedad tan justa que mide sus más pequeños movimientos por la utilidad que de ellos aguarda; tan prudente que si goza aparenta sufrir, y si sufre aparenta gozar; y tan metódica que por regularizarlo todo, tiene hasta días señalados para reir, y días señalados para llorar?» (6).

El segundo bloque temático tratado por Fermín Salvochea dentro de la crítica al sistema, es el referente al dualismo social hombre-mujer (7).

Su planteamiento de crítica a la inferioridad femenina ante un varón que la esclaviza, coincide en su práctica totalidad con las ideas desarrolladas por la escuela fourierista. No obstante, en contra de lo que solían escribir los fourieristas gaditanos en sus artículos y versos, tratando el asunto con una seriedad y objetividad reivindicativa, Salvochea rompe esta dinámica optando por un estilo irónico y sarcástico, describiendo situaciones imaginarias y ridículas, que al fin del caso pretendían decir todo lo contrario. Solamente carga tintes de seriedad en el tema de la prostitución:

"Niéganse a una infeliz huérfana los /.../ recursos para vivir pero / se le muestra como / un Edén el camino de la prostitución. ¡Es tan fácil

(6) Ibídem, 30 jul., 8 ago., 8 y 30 oct. y 24 dic. 1867.

(7) El tema de la mujer como reivindicación social, fue introducido a mediados del siglo XIX en la provincia gaditana por los socialistas utópicos —en especial los fourieristas-, a través de traducciones de autores como A. J. Davis o Czinski, y de escritos de los primeros fourieristas gaditanos,' como José Bartorelo, Margarita de Celis o Josefa Zapata, que publicaron sus arrículos en revistas como El Pensil de Iheria y La Buená Nueva. 
engañar a una inocente abandonada! /.../ la lucha es desigual y la joven queda vencida /.../ al vil seductor la sociedad le alarga la mano, cubriendo el delito...».

Se plantea en primer lugar un muestreo real de los papeles asignados para el hombre y la mujer que generan unos comportamientos concretos, con una impronta de exageración por parte del articulista, concediendo «al hombre la fortaleza /.../ para / ellas / la belleza y la debilidad /.../ la sola definición de los dos sexos envuelve un principio reprobado por la sana razón, y sin embargo sirvió de base al edificio social /.../ la sociedad ha hecho de cada hombre un maniquí».

A continuación, las reflexiones de miedo y respeto hacia la "poderosa influencia de la mujer» da pie a una ironía que hace de las suyas: "ciertas cosas / con el título de / cosas de sociedad, han llegado a la categoría de leyes /.../ y el bello sexo es el tribunal /.../ no queda a los pobres asociados más recursos que cerrar los ojos y dejarse gobernar".

Tal cantidad de "poderes femeninos" justifica en el varón una actitud de control y dominio a la mujer, deseando «tengamos al bello sexo en nuestro favor», o bien suprimiendo sus mejores armas "...que ni mienta, ni enrede, ni murmure, ni tenga visitas, ni pida dinero $/ . . . /$ un collar sin cascabeles".

En una línea más desenfadada aún, asigna un nuevo rol al papel social de la mujer con proposiciones feministas, graciosamente intercambiados con el hombre:

«La mujer en el nuevo orden social /.../ no tendría esa importancia que ella misma ha querido darse. Deber suyo será correr tras el amante /.../ rondar día y noche la calle de su futuro señor y dueño, darle serenatas, declararle su pasión y batirse /.../ para atrapar un marido".

Varias son las comparaciones y símiles a los que Salvochea las somete.

Así, de llamarla "capitana generala», pasando por ser una planta que pendula desde la belleza temprana hasta la mustiedad.

Desde un hipotético contexto parlamentario, ridiculiza su papel tradicional de objeto:

"¡Qué gusto dará ver a trescientas mujeres discutiendo los presupuestos para que nada les falte /.../

-Que hay una declaración de guerra.

- Como una de amor, sobre poco más o menos.

-Un pienso al caballo de batalla, y brida en mano. 
-Que se acercan doscientos mil rusos a la frontera. los rusos.

-Bien, ¿y qué? doscientas mil mujeres sobre la frontera y sobre

Sorprendamos a la diplomacia el más importante de sus secretos, el de jugar sin perder.

-Que caen los rusos prisioneros. Claro que es que ganamos.

-Que cargan los rusos con las doscientas mil mujeres. Feliz viaje y que escriban Vds. en llegando. Quedamos en paz".

Queda también ridiculizado su ideal estético, personificado por un ejército de mujeres de años entrados, que reivindican la derogación de ser el "feo sexo" a un periódico - la propia Revista Gaditana-. La cabecilla se va despojando de pelucas y rellenos hasta que se descubre ser "una suegra».(8).

Es este personaje uno de los más tratados y castigados por Fermín Salvochea, viendo en ella símbolos y exponentes del viejo esquema social, trasnochado e inservible.

Amén de compararla burlonamente con una tarántula venenosa; un gallo de pelea o una enfermedad, le asigna unas funciones concretas en el cosmos social:

«Su misión sobre la tierra es servir de guerrilla en las primeras escaramuzas de amor, de guardia de honor en el casamiento y de tribunal supremo en las querellas matrimoniales /.../ deben gozar, sin contribución industrial ni de comercio, todos los fueros y privilegios concedidos al bello sexo de que forma parte".

A su juicio, la solución de este "problema" pasaría, como todo lo referente al esquema egoísta y degradante de la familia monogámica en buena lógica fourierista, por una desaparición integral de la misma; solución que como es habitual en estos artículos se la despacha satíricamente:

“iEs una suegra! ¡Qué horror! /.../ debe morir señora /.../ no hay remedio /.../ ¿no han engañado ya bastante? /.../ el público llorará como viuda rica, es decir, muy poquito, pero convencido de que en circunstancias críticas, hay que adoptar medidas extraordinarias".

Esta solución de ruptura, pasa también por la que asocia a la suegra como fin y objeto primordial: ser catalizadora del emparejamiento amoroso.

(8) v. Revista Gaditana, 30 jul., 8 sep., 8 oct. y 30 nov. 1867, y 16 ene. 1868. 
El pretendiente de turno no puede evitar el temer "... a una de esas señoras antediluvianas; de esas señoras que nunca han sido jóvenes ni nunca quieren ser viejas que $/ . . . /$ las vemos nosotros, las vieron nuestros padres y las vio Noé a su salida del Arca /.../ monumentos históricos que $/ . . . /$ caja de truenos $/ . . . /$ guarda en conserva para aterrar a los desdichados amantes".

Al final el pobre varón ha tenido que pasar por los suplicios y exigencias sociales con el amor, y además de gastos y más gastos desde el primer contacto hasta la boda, contrae varios síntomas crónicos:

"Náuseas al fijar la vista en una mujer que pase de cuarenta años; desvanecimiento de cabeza al oír hablar de matrimonio; risa convulsiva si se presencia el entierro de una vieja y /.../ el bolsillo como cañón de órgano".

Efectivamente la economía, caballo de batalla social de primera mano, es criticada por Salvochea en otras variantes como los bienes inmuebles o la institucionalización de la dote. Si por un lado "...las casas de los pobres no son buenas, y como la sociedad no ofrece más que lo bueno", por otro "...el empuje de una suegra / está / en razón directa del dote de la niña /.../ porque el ídolo del mundo es el dinero" (9).

Otros temas de matiz social son tocados en menor medida, pero con el mismo empaque crítico: la infidelidad como realidad reconocida en el seno de la pareja burguesa - Salvochea habla de "doncella para todo" y de "seductor»-, o el tema sanitario, cuya situación refleja de caótica y peligrosa para la seguridad de los pacientes, ante una inoperancia profesional que no menoscaba sus honorarios:

"Yo no puedo vivir así, dice Doña Estefanía a su doctor. El doctor que no comprende la enfermedad, sale del mal paso con achacarla a los nervios y los pobres nervios /.../ cargan con el muerto sin apelación. Doña Estefanía quejándose de los inocentes nervios, va liquidando su casa de ahorros, mientras el buen doctor rellena la suya con los nervios de Doña Estefanía".

Sus cualidades de "matasanos» e "hipócrita hipocrático", quedan bien reflejadas en estos pasajes:

"Mejor será que pongamos a la infeliz en manos de un doctor. Es recurso muy gastado, pero, no hay remedio; morirá /.../ tiene unos ojos que matan: doctora en medicina y cirugía le diremos".

(9) Ibídem, 8 ago., 8 sep. y 30 nov. 1867, y 8 marz. 1868. 
No falta además un toque de atención al problema económico-laboral: de la figura del "mustio y triste" cesante, a la cuestión del enchufismo y la recomendación que parodia con un tal Don Dimas, que va a pedirle a Salvochea le haga un memorial para solicitar de un gato sea contratado en un depósito, a costa del recorte de asignaciones a los demás gatos / obreros /. La situación queda rematada así:

"-Sólo temo el que dirán.

- ¿Y qué podrán decir?

- UUna friolera! Dirán y con muchísima razón que ha llegado hasta los gatos el afán de pretender" (10).

Todas estas variantes críticas y precisiones que Salvochea aporta sobre el esquema social burgués, se resumen en dos grandes objetivos: en primer lugar, una ruptura del orden social existente, en aras de otro más real y lógico:

“¿No es un código social el que nos esclaviza? Creamos una nueva sociedad y un nuevo código, y olvidemos esas rancias teorías que nos han conducido a la angustiosa situación en que nos vemos /... dejen que cada cual viva con arreglo a su posición social, sin exponer a un hombre de bien a que comprometa sus intereses y acaso los ajenos por satisfacer exigencias ridículas".

La necesidad de romper apariencias y ostentaciones sociales viene dado, según Salvochea, por la necesidad de vivir de acuerdo con las posibilidades reales:

"Combatiremos ese necio empeño de crear a cada paso jerarquías que obstruyen el buen reparto de una composición dramática / buen modelo social / y privar al público / sociedad / del gusto de verla bien ejecutada /.../ nos duele mucho decir lisa y llanamente que la miseria lo ha invadido todo: porque nos avergonzamos de aparecer tales cuales somos en realidad /.../ confesemos pues que somos pobres y acaben para siempre esos papeles de comedias que tantos sinsabores cuestan".

Estos requisitos no son posibles sin la ruptura, en segundo lugar, de uno de los principales agentes de esta realidad social: la familia. Ello viene dado por un rechazo a la institución matrimonial y por una disgregación de los elementos componentes del clan, pues para Salvochea

(10) Otra vertiente de su crítica a la cuestión sanitaria, se vierte en el sistema homeopático; resulta extraño esta crítica, cuando dicho sistema era por entonces una de las innovaciones en el terreno de la medicina, y sus resultados positivos eran refrendados en Cádiz por profesionales como el doctor de ideología fourierista José Bartorelo.' Cfr. MARCHENA, J. Tesis citada, p. 171. 
la "felicidad posible, es indudablemente la de vivir sin casarse y sin la fatal pasión a que llaman familismo /... / lejos, pues, de nosotros esa plaga de suegras, hermanos, primos y parientes que sólo deben tener cabida en papeletas mortuorias" (11).

En otro lugar de sus artículos, Salvochea desarrolla otro bloque de tipo ideológico y político, en el que, entre otros, ironiza al sistema parlamentario de "hablar mucho para nada", y aparecen alusiones indirectas de hechos trascendentales, como la desesperada situación del país, a través de diversos nombres de mujeres:

"Por lo dicho vendrás en conocimiento de que no hay que contar con Paz, Refugio, Consuelo ni Remedios. Sólo queda en casa Angustias, Dolores y Virtudes /.../ a Prudencia cuéntala con los muertos». En otra ocasión, un diálogo sirve de nuevo para ironizar la situación estructural española: crisis política, económica, social y sanitaria, considerando el modelo tocado y caduco:

«Pues hábleme V. de robos, de calamidades, de miseria, en fin, de cosas de España, y ya verá mi serenidad.

—Que viene el cólera.

—¿Se aumentará por esto la contribución? ¿no?

Pues que venga cuando le den la gana.

-Que hay sarna.

-Eso es precisamente lo que nos hace falta, sarna que rascar.

-Que se susurra algo de hambre.

- Me parece muy bien; yo estoy por la igualdad. ¿Dónde hay paciencia para sufrir que este grito estomacal sea privilegio exclusivo de cesantes y de exclaustrados?, no señor, nada de prerrogativas. El hombre no debe ser patrimonio de ninguna familia ni persona.

-Que se suena algo de peste.

- Son ya tantas las cosas que a mi me apestan, que por una más o menos no he de andar con melindres.

-Que murió Doña Tecla.

- Tanto mejor; ya dio con la tecla de su marido.

-Que no hay una peseta.

-Ni un cuarto tenía Noé y llegó a ser Naviero".

(11) Entre las soluciones que jocosamente da Salvochea, como vía alternativa al matrimonio, está la de meterse a soldado, ejercitarse en gimnasia, vivir en despoblado, ocultar el dinero y «... no pronunciar el monosílabo sí por más mono que parezca y aunque tras él se vislumbre a la felicidad vestida de gala». Ibídem, 24 y 30 jul., 8 ago., y 8, 24 sep. 1867 , y 16 ene. y 8 marz. 1868. 
El desengaño de Progresistas y Demócratas tras los sucesos de "San Gil», hacia los gabinetes moderados o incluso hacia los unionistas - $\mathrm{cu}-$ ya fusión hacia la causa revolucionaria no estaba clara-, podría ser reflejado en estos fragmentos:

"Todos los lazos que los ligaban a la sociedad las hicieron pedazos por vosotros, porque gritábais justicia y dé esta palabra esperaban mucho bien. ¡Y habeis tenido valor para engañar a criaturas tan leales! Si, lo habéis tenido. Es verdad que lo tendísteis la mano de amigos, pero también es verdad que esa mano encerraba un veneno que mata, y ellos aceptaron la mano y: el verano $/ . . . /$ igualdad, fraternidad, justicia y libertad, resuenan por todas partes $/ \ldots /$ al compás de sus cadenas $/ \ldots /$ ninguno conoce que las promesas /.../ son narcóticos en doradas copas y su soñado porvenir la muerte".

Salvochea se deja llevar por los postulados del socialismo utópico, al definir a un hombre que, bueno por naturaleza, "ahoga el grito de su conciencia y encallece su corazón", no pudiendo Dios otorgarle las pasiones ni la razón, optando así por el egoísmo y la degradación:

«El fanatismo disfrazado /.../ convirtiendo en autómatas a seres racionales /.../ hasta hacerle olvidar sus más sagrados deberes. Hombres que habían nacido para amarse se han despedazado como fieras /.../ se rebela el hijo contra el padre por creencias".

Esta degradación humana se traduce en su dimensión social a un bloqueo y falta de entendimiento entre sí / expresión / y a un egoísmo propio que genera el culto a la violencia / beligerancia /.

"Una palabra mal dicha o mal interpretada ha sido la causa de todos los disturbios, que han armado al hijo contra el padre y el hermano contra el hermano /.../ Hemos inventado armas para dar muerte en el menor tiempo posible el mayor número posible de nuestros hermanos /.../ nos han enseñado la manera más segura de adquirir a costa ajena los goces que constituyen a nuestro entender la felicidad de la vida /.../ ¿hemos logrado ahogar las más puras inspiraciones de nuestra alma, reconociendo en el egoismo la única llave del corazón? ¿Hemos hecho algo en favor de la humanidad? ¿Las justàs exigencias de nuestros hermanos están satisfechas?».

Los postulados de tipo demócrata también aparecen, como lógica respuesta al rigor militante de Salvochea, y a las necesidades de propaganda' en el momento ya descrito.

A las proclamas clásicas del "Manifiesto de Abril", la reivindicación de derechos, libertades y constitución, se unen diversas experiencias y ejemplos tomados del Evangelio que en buena ortodoxia demócrata, salpican algunos artículos: 
«Muchos y muy grandes son los peligros que nos cercan, pero la causa que defendemos es santa, y el cielo debe ayudarnos en tan grande obra. No corremos tras cruces, ni calvarios /.../ no queremos más recompensas que las bendiciones de los inocentes /.../ ¿qué es la muerte para el esclavo? El último eslabón de su cadena. El principio de la felicidad ¡Libertad! ¡Igualdad! Justicia! /... ¿ ¿Y no os avergonzáis de pronunciar unos nombres tan sagrados? ¡Libertad! A la sombra de esa constitución tantas veces jurada, dominan tranquilos unos inocentes creyendo poder gozar sin zozobras los derechos de pacíficos ciudadanos; pero vosotros turbásteis su sueño. ¡Igualdad! Confiados en ella os dieron el dulce nombre de amigos; velaron por vuestra hacienda; sacrificaron a vuestro capricho miras de ambición, vínculos de familia».

En algunos casos, preceptos del Evangelio tales como las bienaventuranzas, se mezclan de ideas y valores fourieristas, como la dualidad pasión-moral y el concepto de miseria humana:

"Veamos si /.../ los muertos encuentran lo que el mundo no me dá; algo bueno $/ . . . /$ dichosos los que sueñan despiertos. Ni la opulencia les embriaga, ni la ambición los ciega, ni la miseria los esclaviza /.../ porque ya no tienen que temer ingratitudes, perfidias y desengaños y porque $/ . . . /$ han dejado a la puerta del sepulcro todos los harapos de la miseria humana".

La irrupción en la década de los sesenta en Cádiz, de los principales impulsores del movimiento krausista, Alfonso Moreno Espinosa y Romualdo Alvarez Espino, generó una corriente favorable de fuerte arraigo en la ciudad, en especial, en los círculos pedagógicos e intelectuales; labor que tendrá sus frutos coincidiendo con el inicio de la restauración borbónica. El krausismo, que postulaba por una reforma integral del hombre, la sociedad y las instituciones, a través de la idea de la razón, en el ámbito de la religión y la naturaleza, tomaba en parte aquella idea de encauzar al mundo en un principio unitario, que abarcara astros, plantas, animales y hombres; por ello cada uno de estos elementos debía ser respetado, lo que generó toda una corriente protectora de animales y plantas. Corriente esta que fue asimilada por muchos teóricos, como el propio Fermín Salvochea al referirse al sacrificio de los perros callejeros, otorgándoles cualidades y virtudes carentes en el propio hombre: "¡Y se hablará de fieras! ¿Qué mayor fiereza que el mismo hombre! /.../ ¿Quién os dio el derecho de destruir una de las mejores obras de la creación? ¿no caben por ventura en el mundo unos seres que nacieron para hacer las delicias del hombre? ¿no queréis tener un verdadero amigo y compañero en este valle de amargura? /.../ halagáis a la mujer y 
dáis muerte al amigo verdadero! al servidor fiel, al que daría por vosotros su vida y cien vidas" (12).

Constatamos algunos fragmentos de indudable contenido filorrevolucionario que denotan un desenlace, o al menos, una preparación de la insurrección muy avanzada.

En una alusión directa a Cádiz, Salvochea derrama de su pluma grandes dosis de dramatismo y desesperación:

"Cádiz, la heróica Cádiz, la que en medio de las borrascas que agi$\tan$ a la Europa entera, había sabido huir de los escollos y evitar el naufragio, acaba de perder en un momento de error los hermosos títulos de culta y católica. Rotos los diques que la religión y las leyes oponían al desenfreno y al libertinaje, por donde quiera que volvamos los ojos, no vemos más que lágrimas, ruinas, desesperación y sangre. ¡Qué cuadro tan horroroso presenta una ciudad sembrada de cadáveres!".

Otras reflexiones, entre agosto y diciembre de 1867 , denotan cierto desánimo y nos dan una idea de la revolución con apariencia de empresa difícil y lejana, debido quizás al intento fallido de agosto-septiembre del mismo año:

«No me preguntes ya cuando concluirán los plácemes, norabuenas, felicitaciones y aguinaldos /.../ es preciso que el sol salga de su retraimiento y lejos de eso, continua muy tranquilo echándose fresco /.../ para dar con esa señora, sería necesario armarse de muy buenos instrumentos astronómicos y dar un paseo hacia el Cabo de Buena Esperanza, y con todo y con eso quizás no viésemos al cabo más que la buena esperanza, y esa convertida en tierra".

No obstante, otros escritos del mismo período, bajo la tapadera de criticar la muerte de unos perros callejeros, expresan una fuerza reivindicativa y alentadora, e intenta contagiar y provocar la fiebre revolucionaria por cambiar el sistema vigente:

"El reinado de la verdad ha de empezar por un trompetazo, y para darlo se necesitan alas. Por no tenerlas ha habido tantos mártires /.../ a vista de tantos crímenes la sangre hierve en nuestras venas; el corazón quiere salirse del pecho y para mayor dolor ni aún llorar podemos ¿Por qué, pues extrañar, que aceptando todas las consecuencias de nuestro arrojo, nos presentamos hoy como defensores de los desgraciados /.../ inocentes, cuyos derechos vamos a reclamar; pero si en tan sangrienta

(12) En esta dinámica krausista de defensa de los animales, critica a la Navidad por el sacrificio multitudinario de "...dos millones de bichos de pluma". Ibídem, 24 y 30 jul., 24 y 30 ago., 8 sep., 24 oct. y 24 dic. 1867 y 8 mar. 1868 . 
lucha quedásemos vencidos, quizás otros siguiendo nuestros pasos con mejor fortuna y menos obstáculos, lograran afianzar el reinado de la paz sobre la tierra, y derramaran una lágrima de gratitud sobre el sepulcro de los primeros adalides /... / una voz del centro de la tierra nos gritaba venganza, y su eco resonaba por el espacio /.../ se reanimaron nuestras fuerzas debilitadas /.../ y en todo el valor que infunde la desesperación juramos no descansar hasta exterminar a los opresores. Las sangres de las víctimas humeante todavía, reclama el castigo de los culpables. La hora de la expiación ha llegado, miserables. Si la justicia humana olvidase su deber, un poder sobrenatural abriría las tumbas; se animarían de nuevo los restos de tantos inocentes, y ellos mismos lavarían con vuestra sangre la mancha que habéis echado sobre su preclara progenie" (13).

En suma, definimos la labor de Fermín Salvochea en estos artículos anteriores a la revolución de septiembre de 1868, como la elaboración de una teoría, que, salpicada de conceptos e ideas fourieristas, demócratas y krausistas, preconiza un nuevo orden social, partiendo de una ruptura con lo establecido; en especial lo referente a los valores sociales, el dualismo hombre-mujer y la célula familiar monogámica. Los sometimientos de la Imprenta a una dura legislación durante el período del rejnado de Isabel II, hacen este balance teórico de Salvochea en la Revista Gaditana, equiparable en Cádiz y su provincia, a los escritos societarios de Ramón Cala, publicados en 1866 en la Revista Vinícola Jerezana (14).

(13) Ibídem, 24 jul., 24 ago., 24 oct. y 24 dic. 1867.

(14) Cfr. MARCHENA, J. Tesis citada, p. 126. 
PERIÓDICO

\title{
DE INTERESES MATERIALIS, CIENCIAS, LITERATURA, COSTUMBRES
}

\author{
Y TEATHOS,
}

\section{DIRIJIDO POR D. VICTOR CABALLERO Y VALERO.}

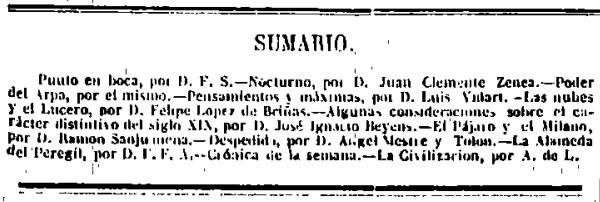

PUNTO EN BOCA.

Cada cual es muy dlueño de decir lo rue se le antoje; será capricho, necedal, mania, hasta locura si se quiere, pero yo 1 o pucelo remerliarlo; natio me qui-

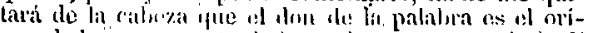
fon de la major parte de los males rue nos rodean. Y no se me digit ruc la lacultad de hablar fué, como muchos creen, el regalito sle luxha rue hivo a nuestros primeros parlits êl simpremo lliceulor. Ni en arpefons lélices tiempros liabiat lis perniciosa costumbre de hacer reigalus, ni bios judo prensar en alligir al hombre con muevas calamidadustruanto eomo por via de ensayo, ó siu durla, $y$ es lo buas probable, con el tin de irlo metienda desile chipuito en los trofes do r'ontribuyente, te hatria sacado uma costilla, yue es conı si dijéranos, la primera contribucion de immuebles. No ha sido port cierto mal mueble la tal costilla: pero dejemos á un linlo los huesos y ramos á lo que importa

Lo que hubo lué, y nome desmentirán los periódicos de aquella época, fure reconociendo Eva su poen mirito, porrute en efecto era muy poco, como sucede á todo lo ifue st halce de iretazos; y deseando sacal al gun partido, imujer al lin! wechó mano rle la serpiento como de un matestro do lenunas, para porler lecir cuntro piropos a sll marido, puien no tenia todo lo de salomon, por la sencillisima razon de yue salomon no habia nacilo torlavia. Ifabló por tin mamá, y entraño á papá. Tor cisa moda no pasan años.

Me parece efuc lo ilicho lonsta y sobra para probar que el don de la malabra no turo el prectaro oirigen que algunos li: atribugen. Resta siber si descle ot paraiso liastit nuestros dias ha desmentido su infermal estir'pe el supuesto rewritito.

lie él, como de una plarat, sé valió el mismo bios cuando ruiso castigar in la torre de Rabel ut orgullo de los pedantes. ¡De tan atrís viene esa fannilia! Si lo que alli pasó fiué ó nó de trascendencia, con lar una vuelta al mundo saldremos de la duda. A estas loras no hemos porlido entendernos: contimuanos en Baluel sin novedad; pero dejemos las torres porepue á ciertas: alturas es muy lácil perider la cabeza, y examinemos la llanura que no es tan llana como parece.

Si echamos una rápida ojcarla ileste la muerte de Mbel hasta la revolucion de francia, que, entre paréntesis, es una señora ojeada, 'siempre huillaremos que una patals'a mal dicha ó mal interpretada ha sido la causa de lodos los disturbios, rue han armado al hijo contra el parlie y al hermano contra el hermano. Y si desdle los asesinatos á mano armada pasamos á los que hacen sir armas los podadoress dol género hurnano, ravidicas, para cun todos me entiomulan, no poulremos Inenos do encontrar una palabra sirviendo siempre de cscuilo, parapeto $\delta$ muralla real para jugar á mansalva con los que innoramos la epidémica fraseologia de los Hipócrates y de los Galenos.

- To no puedo vivir asi, dice doña Estefania á su doctor. El doctor ique no comprende la enfermedad, sale del mal paso con achacarla á los nervios, como los polires nervios no encuentrau lelrado rue ios delienda, curran en el muerlo sin apelacion. Boña Estefanii quejimilose de los inocentes nervios, vá liquiclando su caja de ahorros, mientras el buen doctor rellena la suya con los nervios de doña bistefania. ¿Qué mina dal l'orí ha dado mas plata que los nervjus?

Serpentea por todas partes otra palalora muy parecida a los vinos viejos. Con cuatro letras, que equivalen á cuatro gotas, se trastorma el cerebro mejororganizado. Tiene treinta y seis grados cubiertos como el mejor ng gurdiente catalan, y como él, alegra en el primer momento y dá sueño en seguida; delifita i unos; a otros enloquece. El número de sus vietimas se cuenta por el de sus prosélitos, y, sin embitró, en el sontir de los contemplativos es un idestello de la divinidad: esto la llama alimento del aluna: aruel áncora de satvacion: para paladares poco delicados, es duizura. Uno nos la presenta en figura de niño antojadizo; entretenido en argujerear corazoues, como si el corazon luese zaranda ó rayador de queso: otro mas prulente y menos confialo la pinta en figura de perro perdiguter, y no falta quien crea que es un fantasma para alucinar á los incautos; pero en tan confuso laberinto
át quién hemos de dar crédito? 
mi palotada, no libulsearía en decir que la tal palabra, talcinada ante todo, doberia ostar ontre los minnos botos de un limacéutico con órden oxprisia de no despachar ni un dracma, sino en ciertos casos desesperalos, que desesperado y algo mas os inenester hallarse para necesitar un dracina de amor.

Si desde los males que alligen á uncionos enteras damos un salto í los quo hormigruean en las casis de vecindad, que no es salto tan mortal conno parece, siempre hallaremos los fumestos resultados de cse don tan ponderado.

Perico el feo, liene cuatro palabras con Cirro el de los rizos, y de sus resultas Satunús caryan con el leo, y los escribanos, que se agaryan de un pelo, cargau con los rizos de Curro y con Curro por añadichura. jentiva parece que pol cualro palabres se den á todos los diablos dos amigos!

Encarnacion la chata, homra thel barrio, cree (o)no articulo de lë, una palabra yto le ha dinto su Puco, pero bien pronto la homra de Encarnacion anda, como su nombre, de boca en boea por todo al barrio, y se queda la Chata con un palmo de natices, porinue el buen Paco no t puiele lar mas que valabins. I a gente de alta sociedal suele hacer lo inismo que Pico, preso de alta sociedide de alta soviedad son prelebres de honor, lo que quiere lecir ifue la alta sociedad tiene otro juerro de palíbras.

Magdalena la moñona, flor y mata de las esposas, dice sencillamente tha palabra á su compalie: el marido la toma por domb quema, y aturques Magdalena llorando mas que uma Mlardalena, jura y perjura que no hay tales cirneros, riñen los compadires: la Munona deja de ser hor y nata, y el esposo carna con otras' esposts que la justicia le l'erala, porque dió un mete y saca á su compadre á comsecuencia de la palabra rque y saca á su compatire a collsecuencir.

Pues si clesile las potalitins sueltas pasamos a las frases, hallarimos inuchas touy seductorits g muy inocentes $\dot{a}$ primera vista, pero examinadas detenidamente, pierden de inocencia lo fue granan ile suduccion.

- Para alinilarme su casa don Restituto me exigre un liador,-dice doña Prudencia á don Clementu,Querra v. ccliar una firmita por mi? Jhi la castalidad que esta buena mujer, que lienc el alrevinniento de liamarse Pruelencia, es lia de una linda muelitula de ojos negros, á ninguno so le ocurre yute tuma lirma pueda ser mas negra todavia. No queda pmes, it ini señor don Clemente otro reeurso que Lomar lit plituna y dejarse desplumar por doña Pludencil, quinen su queda tai hueca como si hubiese dado con cl hovimiento continuo. Bien es verdad, que pain una tia, esto de vivir por cuenta do los ojos de su sobriua vala seguramente algo mas que ol movimiento jor contínuo que sea

- Quiere V. pasar cl rato" dice don Modestu a su amigo Daniel: jugraremos un buro. Como el priucipal papel se cede por politica al convillato, jutitudo

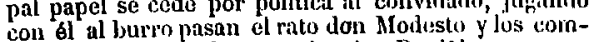
pañeros de don líolesto, y el amigo lDanithl so chruenttra sin saber cómo, en el lagro de los leones.

Pues parque estas frases y otras patericlas i ustas me hacen temblar, hay yuien me llaira cobiude. jtiobarde yol Yo no soy colmude, no señus; Lengro diutas pruebas de valor, me lio casado, y por donde quiera que V. me busque, encontrati en mi tolo un homque V. me busque, encontria tue baja, me pueslo tan tranquilo como si no bajaso, y si el yue bija no es turco sino el tres por ciento, yo impasible siompre. libion

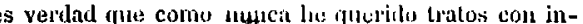

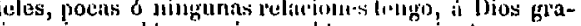
as, ni con el tureo ni egur el lies por cierito.

Pues háblems: V. deroloss, le citamidades, do miseria, en fin, de costas de Espinia, y ya verí mi serenidad

- Que vieno el cólerin.

- ¿Se aumentaú por esto la cuntribucion: ¿Nó? Pues yue venua cuamilo le dí la gami.

- Que hay sarna.

-Eso es precisamente lo que nos lace falta, sara que rascil'.

- One se susurra aluo de handure.

-Ne parece muy bien; yo estoy por la igualdad. ¿Dómile hay paciencia pitra sulvir ruc esto gifito estomacal sen privilegio esolusívo de cosintes y do esclaustrados: No scinol, daala de plirogativas, lil hamlire no debe ser palrimontio le minguna familia ni persona.

-Quo se suena algo de peste.

- Son ya tantas las costes yue a ini ue apestan, que por una mas ó menns no ho de andar con molindres.

- Oue murioj hoĩa Tecla.

_-Tanto unejor"; ya dió en la tecla sil jutarido.

- Que no hay unia pescla.

- Ni un cuarto tenia Nó́ y llougó a ser naviero.

Pues un hombre de ini teniple, mo hombre yue $\sin$ lisonja, pudiera pasar por un Niepoleon, se echa á tem-

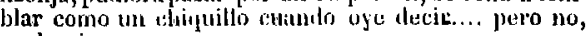
no lo viga jo.

No asusta un toro á Pones y se puerlaria lamañito

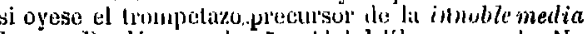
luna. Perdóncme el suñor' Aludul kílian sogundo. No intimidan las balas al militar arueridido y palidece anto una ódelen de reemplazo. No ciusan pavor it una

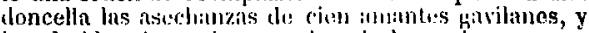
la sola idea de norir con palina le lace alorrecer.... hasta los dátiles. Pues uma cosa miıy parecida me sucerle á mi cutanlo me dicen: monono mio, yo te adoro. iSalnes tí, carisimo lectur, fo yto quitere tlecir este monono mio tin dulce y tan seductul? isalues tú lo quo cuesta en eslos timpos llogra a nerecer el nombre de monona? Monono mio, en boca de una

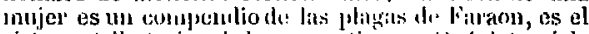

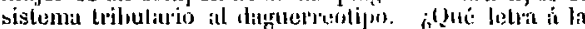

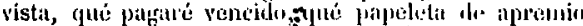
apremia tantu como uri momono mis:?

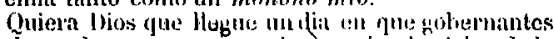

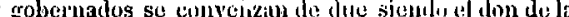
palabia la causa de todos los malles gute nos alligen, no queda mas pecueso que heventar ina iueva bandera pua lieve jom loma

TUNTO FN BOC:I

ir. $\mathrm{s}$.

\section{NOGTURNO.}

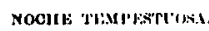

A mi amigo Nioolás Azoárato.

Murió la luna:-ol ángel do la nieblna

Su castiver rucoge en blanen gisu;

$Y$ en un monto do rnyos y tíniclias

El Dios dul huracan atrualto phan. 


\section{Airutgitn (Grititam.}

PERIÓDICO

\section{DE INTERESES MATERIALES, CLENCIAS. LITERATURA, COSTUMBRES}

Y TEATROS.

\section{DIRIJIDO POR D. VICTOR CABALLERO Y VALERO.}

\section{SIMARIO.}

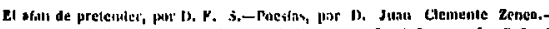

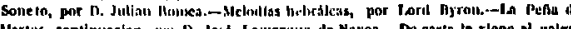

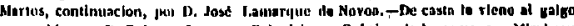

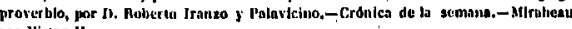
por Victar itugo.

\section{EL AFAN DE PRETENDER.}

Comocada cual tiene sus manias, á $\mathrm{m} / \mathrm{me}$ dió dosde chicuito porr eserilie bien, es decir', for' hacer letras muy bonilitis. Mo yarccia que con esto tenin lo bastante para adifuirir un nombre. Fista cra otra ilo mis manias, y son clos.

MIny poco liumpo bastó para conseguir, entre mi familia so entiendo, el titulo do pendolista. Conviene saber que mis padres regalaban al maest'o el dia do su santo y el det mio su durito colummario, porique en aquella ćpoca no' habia por fortuma mas nopoleones que el capitan del siglo; su pivito por pascuas; la velita el dia de San' Casiano, y otra mayor el de la Concepcion. Jin cambio me daba ùl en calidad de reintegro, por supuesto, una medallita con cinta de medio liston, rue yo le revolvia a ocho dias vista con liston enter'o; siempre cressendo.

Con esto sistema do compensaciones el maestro quedaba tan contento, y yo loraha de ro\%o, viendo on cada medallia no las particulas del pavo y de los mejicanos, sino el premio dehido á mi talento. Desde entonces mo muero por las condecoraciones. Otra de mis manias y son tres.

Sali de la escuela, y como para pedanle no me faltaba ya mas que subir un escalon, lei el Bertoldo, la Alala, el Arte puélica fácil de Masdeu, y lay cartas de Abelardo y Eloisu. Con tan vastos conocimientos me consideré desde luego otro lloracio Flaco, aunque an honor á la verdadl la consideracion no cra muy exacta, porque á la edad de guince años pesaba yo 5 arrobas y 7 libras nelas. Sin embargo, desde aquella epoca empecé á llamarme literato. Fista es otra de mis manias, y van citatro.

Empecé por escribir la cuenta del gasto diario, que me daba el mozo, y algunas epistolas amorosas que yo le daba á la moza. 'Esta mania, que he lla- mado siemple la capitana generala, me ha dado mas malos ratos que torlns las otras. De aqui proviene sin durla mi aversion á todo lo que huele á tropa.

Ile querido principiar, por mi hiogralia, porque me parece de sumo interćs conocér á quien se habla.

Sabiendo ya Vils. de buena tinta hasta donde llega mi erudicion, $n$ n estrañarán les diga que soy el paño rle lágrínas de todos los pretendientes. Se presenta en cl paseo una cara bonila. Ya estoy rodeado do amigos, que me piden, no la niña, sino una declaracion de nmor para la ríña.

- Homlro, yre no la conor.co!

- No imporla. i'lú quo escribes tan bien!

- YY quó escribo' respondo' en seguida, orgullecido al ver que mi lamo ha llegado hasta las personas, que me necesitan.

- Gunlquier cosa, hombre. ¡Es encantadoral

- j'Te pareco que la llamemos satétite de Cupido? - Perfectamente.

Tiene uins ojos que matan.

-Doctor'a en medicina y cirujia, le clirúmos.

- Roba los corazones con su sonisa.

- La amenazarémos con dar parte á la policla.

-iBien, muy bien; como cosa tuya!

Yo me sonrio al considerar que mis cosas son cosas, que gustan á todo el mundo, y continúo echando flores á mi bella desconocida en cambio de las que me echa mi amigo sin conocerme á fondo, ó mejor dicho, por conocerme demasiado.

Llega esa época anti-económica y subversiva; á la que en vez de llamar carga a la bayoneta, dan el nombre de pascuas los que cohran, y el de ascuas los que pagan. Ya tiene Vd. mi casa hecha un jubileo. El sereno quiere una octava, real por supuesto, un soneto el cartero, y el repartidor de periódicos, mas matemático que aquellos, una décima para diezmar á la poblacion, y entre ellos que piden, y yo (ute escribo, sembramos ol luto y la desolacion por todas partes, quitando al mas pródigo hasta las ganas de serlo.

Vaca un destino $\delta$ retoña otro viejo, y.... jaqui fué Troya! jCuántas caras, verdaderos retratos de la que tiene cara de hereje! jQué gritos! IQué confusion! Mas fácil me parece hallar la cuadratura del círculo, que convencer á un pretendiente de que no tienerazon para pedir lo que pide. Pero yo escribo, que es 
mi manía; ellos solicitan, que es la suya; y sucede por lo comun que ellos y yo perdemos el tiempo, mania muy española, y muy generalizada entre nosotros.

Que entre tanto pretendiente habre tenido lances originales no hay para qué jurarlo.

-Yo soy turco, me decia uno.

-No como hoy mas que tocino. Si quiere Vd. acompañarme...

- Lo que quiero es ser liel...

-Dificilillo me parece.

- Del matadero.

-Ya no me parece lanto.

Solicito, me decia otro, un privilegio para vender pildoras, que curan todas las indigestiones.

-Tenemos en España medicina mucho mejor.

- Cada cajita una onza de oro.

-No es mala pildora. ¿Y qué nombre tienen?

-De los cuatro ladrones.

- Pondrémos de los cínco si Vd. es el encargado le venderlas.

Pero entre todos los aspirantes, el yue inas mo ha llamado la atencion es uno que.... iquién podia ligurarse que D. Dimas!... Supongo que Vdes. sabrín ya quión es D. Dimas? Pues tan formal y todo, con sus.espejuelos azules y su peluca, se presentó en casa, y como segrun me dijo, parece que on el presupuesto del depósito hay una asignacion para.... Ali es anada lo que venia pretendiendo! [ej'o no desfigntremos los hechos. La conversacion tuvo lugar en los términos siquientes.

-Servidor de Vd.

-Beso su mano.

- Vd. estrañará que sin conocerle me tome la libertad de pedirle.... Pero zqué es eso? jSe pone Vil pálido! ¿Le hà dado á Vd. algo"?

- Es un achaque que padezco desde ln extraordinaria de guerra.

- Pero si yo le hablo en sana paz.

- En sana paz, y empieza Vd. pidiendol

- Tranquilícese Vd.; no se trata de dinero.

- Me ha vuelto Vd, el alma al cuerpo.

-El caso es que, yo tengo una morisca, á quien quiero como á las niñas de mis ojos.

-No es Vd. el primero que en materias de amor se pasa al moro.

-Y como es muy natural, deseo proporcionarle una colocacion decente y productiva.

- Hable Vd, á cualquiera de los empresarios de toatros. De mujeres estamos muy mal.

- Es que mi morisca no declama; lo que hace es cazar.

- ¿Se ha educado en Inglaterra?

- No señor, en un convento.

- La morisca! ¿Está Vu. seguro de ello?

- Como que yo mismo la saqué.....

- ¿Y qué piensa Vd. hacer con esa infeliz?

-Quisiera que entrase en el depósito.

- En al depósitol No puedo comprender....

-Si por rnedio de un memoriálito consiguiéramos que la asiguacion señalada a los.gatos en el presujuesto, re :ayese toda entera en mi protegida.... j Cazadora cono ella, con dificultad han de encontrar!

- Pero, hombro de Dios! jQué me está Vd. diciendo? ¿De quién me está Vd. hablando? isca.

- De quién he de hablar! De mi gatita; de la mo-

- Yo escribir para una gata! Ni que Vd. lo piense.
- Adonde vamos á parar si hasta las gatas se nos vienen con exigenciast:

-Pues si Vi., que liene tanto talento, quisiera... -Y ¿qué podila hacer? Vamos á ver. ¿Quién escribe hoy un mernotial siu recopilar servicios anteriores, padecímientos, emigraciones?.

- Ella emigró del convento el año 35.

- Ya eso es alyo.

-Desile entonces ha pasado muchas liambres.

-De ese mérito no debemos hacer mencion. Tendriamos puchos competidores. MIejor será echar mano de su álbol genealógico.

--Su madre lué morisca tambien. Esto clebo dar-

e cierta importancia...

- Seguramente. Herodar hoy aunque no sea mas

que el color de nuestros milyores, siempro es algo.

- Su vadre lué maltés.

- No diga Vd. más. De fijo es cazadora. ¿Y el pelo que tal? -Corto y fino.

- ¿Y el ojo?

- Je prelendiente.

- ¿Y ollato?

- De cosanto.

- ¿Cara?

- De pocos amigos.

-Y da génio, qué tal?

- Es española. En díndole dis comer, materia dispuesta para todo.

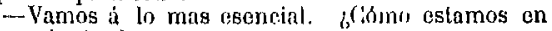
cuanto í uñas?

-Perfectamente; annque corlas mon finas, porque para ovitar el roce continuo, no tenido la precaucion e cubrírselins con un guanta linilo.

- ¿De cabritilla? jAlignllico! ¡Magntlico! Que solicite, yuo pida, ulue exija. la morisca de Vd, acabará con toda la gente roedora.

-Con que, si Vd, gusta, empezarémos el memorialito.

- Solo temo el qué dirín.

- ¿Y qué podrán decir?

- Una fioleral Dirán y con muchísima pazon que ha llegado hasta los gatos

\section{EL ATAN DE PRETENDER}

F. S.

\section{ORA PRO NOBIS.}

Af uere al sol; la nocho llega,

Su manto ol áura dospluga

La lua empioza de nacor,

Todo al reposo se antres.

Niña, ¿qué debos hucer?

Debo acerearso á la orilla

La ligora navecillu,

Dubo el homiro doscansar,

Dobo dorwir la avucilla,

$\mathrm{Y}$ un alma luena rozar.

Quién enle culntos tiranos

Multratan 6 tus hermanos

$Y$ cú́ptos gimon á soles

Y cúcto alom

Buscando apoyo en las olas!

Ruega, ruega y en tu anhelo 


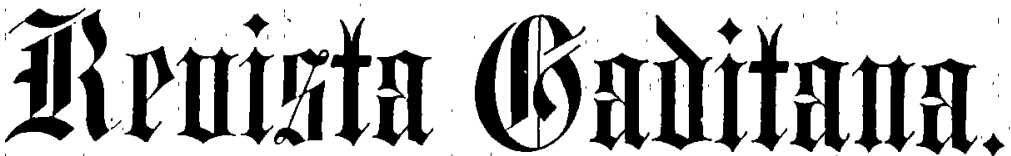

PERIÓDICO

\section{DE INTERESES MATRRLALES, CIENCIAS, LITERATURA, COSTUMBRES}

Y TEATROS.

\section{DIRIJIDO POR D. VICTOR CABALLERO Y VALERO.}

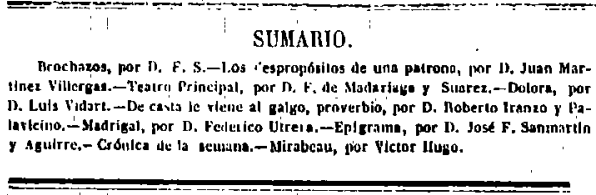

BROCHAZOS.

\section{Carta de Jún Niega á ou amigo Roque.}

Mi querido Roque: hemos yecibido has clucherius que mandas para tu ahijado. 'Tonto de mi! Pues no iba yó á darle el almanaque cuando me pedia tonos Los s.xntos! Ya se yé, iquién podia figurar'so que lo que el angelito tueria era frutal Vaya Vol. ń entender al que no pide las cosas por su nombre, pern á esto te contestan, ufuo si á calla cosa se le diera su vel'dadero nomlu'te, nos asustaria el nombre de muchas cosas. Y mira tí, es muy cierto. Tiøúrate rue así sin mas ni mas te digera uno de buenas if primeris, noque, vengo a ltevaring todo lo que tienes. Gomo tí, á Dios gracins, no eres doncella para deoirin todo amen, lo mos naturial ori que no te dejases rolotr. Pero si te dice, señor clon ltopue, y to la la mano, y te hitbla de hotior, de gloria, de deberes sociales, y de riama pósturna, y te pinta la exigencito con medias timtas muy dulces de probidad, algunos toymes ito justicia, y nata do somlims de tirania, auntue veas en el íl'timo térnino dol cuadro una ligura parecida á perro de presa, como ustí ailit á lo lejos y entre nubes y ú no puerles sospechar que hasta en las mules hava perros, zqué has de hacer sino soltar la jresa? Esta es una de tantas ciertas cosas, que si pasara a la categoria de cosas ciertas, se llamaria permula. ¡Cuinto mas bonito es el nombre que hoy tiene!

besde que el clsico recibió la fruta no nos deja : sol.ni á sombra. Parece el inocente un vástago del sistema tributario. Mira si suena con ella, que leyendo yo uno de esos discursos, en que so nos dá por seguro que estamos ya en la antecamara de la felicidad, y á dos pasos de esta señon, como el muchacho mén vid tan contento, se vino á mi griländo ton Jos brazos abiertos; esa es castaña, papá. Bolsa, decia yo ojean- do otra columna del periódico; los títulos del tres muy solicitados.-Mamá, mamá, en la bolsa están muy tañas, y no quiere dármelas papá.-Deuda sin interés; no hny plata.-Esa no es castaña, papá, y ponta el angelito una cara al decir esto, que daba compasion. En un artículo de política esterior nos cogió el sueño, y al despertar, vino An bustias á recordarme que era dia de dimintos.

Los peros no le han gustado al chico, pero no lo estrañes. Como de Madríl nos envian continuamente tantos y tan hermosos... Y no vayas á creer que todos se crinn allí. Ios mas gordos son catalanes. Tienen un color doralito, yue se 'mete por lo's ojos, pero clivales th diente. Mas agrios son que un empréstito forzoso. Esta finta no puede comerse cruda, pero asadn te gustaria. Tu ahijado estuvo á la muerte por comer un pero, que sobre ser tan malo, no estaba en sazon, y desde entonces lo mismo es ver uno, lo tiemblan las carnes al pobrecito, y por mas que le aseguro que los que tí lias manulado no son catalanes, él contésta siempre; hunqu: sean franceses, yoi no quiero perns. Y hora y paten, pero como la mailre sabe tanto, le dá una castañita y... santo remedio. Brinca de gozo, y se rie como un tonto. Fso tienen de bueno los chiyuillos; con cualiguier cosa se les contenta. Mira tí si una castaña no puede hacer mas daño que un pero. jlo que hacen los pocos añosl. Dlchosa edad. ¿Con ilue exiges que te cuente todo lo ocurrido en casia deside que no te escribo" Vamos, por eso viene el porroncito de miel. Has querido mandar en gefe y empiezas con cuatro dedadas dulces. Ya puedes erhar bellotas; no faltará quien te aplauda, y se las

Yo bueno á Dins gracias; y siempre con el deseo de dar uni vuelta al mundo, pero Angustias no quiere España, y yo sin mi mujer no doy un paso.

En la lamilia ha habido sus altas y sus bajas. Patrocinio so casó con Justo, y tuvieron fruto de bendicion; Venturita; pero la niña voló al cielo, y ellos se an sepultato en el museo cle antiguedades.

Mariat de la Paz desde que salió de Navarra, empezó á enfermar. En Francia le iba muy regularmente, peru do la noche á la mañana se le pegó una calenturita, que la iba consumiendo por momentos. Los médicos la aconsejaron que se fuera á Italia, porque aquellos aires eran muy puros. Ella tomó el con- 
sejo, y en Italia murió la pobre Paz. Como todos sus ocasiones ha habídu en gǘe por no inatar, ni el ham-

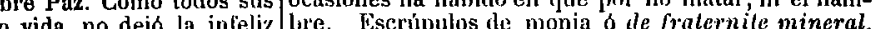
bienes los habia repartido en vida, ni un real, pero eri Francia tenía amigos, y ellos col'rieron con los gastos del entierro. Inglaterra tendio el anteojo, que es su mano derecha, y dijo very wucll que significa acompaño d Vils. en sil sentimiento; cosa parecida. Son muy linos los ingleses.

Esperanza en Cientuegos, Candila en Sacrillcios Milagros en el Rio de la Plata, y Nieves en Paris de regreso de Méjico

Caridud en el Imperio Celeste. Por si no vualve, hace aqui sus veces una comedianta que nos tiene siempre divertidos, porque asi se disfraza do torero como de turca, y juega y baila y canta que es un primor. Poses una buena vo\%, quo es lo que priva, En esta parte hemos ganado, porque la difunta era muda.

De Modesta hace burla toda la vecindad, pejo un saboyano la obsequia, porgute cou lichos ruros busean su viua estos infelices.

Dolores no encuentra quien la quiera. A Virludes le sucede lo mismo, y Clemencia no liene boca para despedir á importunos,

De Remedios nada te digo porque nala sabemos. Tuvo unas contestaciones con la familia y se marchó jurando que no volveria por España. Consuelo se fué con ella, y tampoco ha vuelto, uunque nada juró.

Mercedes en Madrid, pero se ha dudo tan poca importancia que nadie hace ya caso de Mlercedes.

Prudencia cada dia mas consumida. Se nos vá por la posta, y es un dolor, porrqus hace mucha falla l'ridencia.

Refugio en Manila. Alli le vá mejor de su ahogutio.

Transfiguracion en Viena, y Clarita en Berlin. IY si vieras qué bien se vá esplicando! Asi tiene á todos con la boca abierta. Ia labla el alemin, y el ruso, y el italiano, y está aprendiendo el griego, y á su tiempo se enredará con el inglés, y al francés no le entra, porque dice ella que tanto vous, vous, no sirve mas que para asustar chiquillos.

Victoria deslumbrando í los jugadores con prertdas de acero, pero como los triunfos son lágririas y sangre, el hierro perderá su brillo y ella el juego, que la moneda de Victoria debió ser el lalento, persico, babilónico, ó don del cielo, que es ol mejor do los tilentos.

La desventuradá Polonia con tubérculos en el pulmon, pero tan liermosa, que aun dormida, quila el sueño a sus rivales.

Por lo dicho vendrás en conocimiento de que no hay que contar con Paz, Refugio, Consuelo ni fiemedios. Solo quedan en casa Angustias, Dolores y Virtudes, que no levanta cabeza desde que perdió el pleito. A Prudencia cuéntala con los muertos. ¡Mira euán reducida una famllía tan numerosa!

$\mathrm{Me}$ parece que no te quejarás; he cumplido tus ordenes al pié de la letra, y si algo me dejo en el tintero es por no manchar de borras el papel, que tiene muchas el tintero de casa. Pagado y con creces el regalito, voy á contestar tu carta, que pica en historia.

Has de saber que entre mis muchas debilidades tengo la de creer, impresiones del viage, que es un crimen combatir el error, porque slendo la mentira ol alma de la sociedad, no podemos sin ser legisladores $\delta$ médicos, separar impunemente un alma de su cuerpo. Esto serú todo lo estúpido que tú quieras, que porlone Vil. por Dios, hermano, es en sociedad que porclone Val.

Hecha esta htimilde confesion, claro es que tu lianqueza no me agrada. El reinato de la verdad ha de empezar por un trompetazo, y para darlo se necesitan alas. Por no tenerlas laa labidilo tantos mártil'es.

V'enirsunos con la rancia leoría de que ros y dos son cuatro, cuanda.nos asusta lic iilea de! llegar á saer cuantas son cinco; atreverse a indlcar que son telas de araña esos veneros de riqueza, que tanlo papel lian hecho; sostener que un vilor, paril ser lal, ha de porler encontrur siempre que lo husque, su equivahente on use reculator universal, i veces niño pródifro y antojadieo, í vecos viejo avar y cruel, que se llama moneda; no permitil que d doralo sustituya al oro, cumo los honores al honor, la allilacia al talento, y la ostentacion á la caridad, bl no us vonir lraspapolato de la biblioteca económica tlu Ilerodes, es por lo menos remontarse a los ticmpos do la andante caballer'is.

Baja de esas alturas al munulı matavedi; no me atrevo á ltamarlo real por no despertar al señor ininistro de llacienda. Baja y verás fule ell esta jnansion de delicias no hay como los limiest's para conmover arrebatar.

Aqui um perlimista ofrece aceitu pin'il que retoñe el pelo hasta on ol cuero de sus lutis, y si no las presenta bramando, es porque uso lu harán los consuiidol'es.

Aili un Dulcarnara ridministra pildons, que curan todas las entermedades, y.si no mata la eslupidez, es oorytle de ella vive.

Este quita rnauchas y aluo mas que no dice. Aquel traslada lunares de la conciencia al rostro. Uno dá la manera de roer huesos, y otro en fin, mas atrevido mas sublime,.mas artista, conviurte el algoulon y e alambre en una mujer, toda rajor, toda ifusion, que no hay mas que ver para morit'se, lo menos malo si de amor se lrata.

Fil estudio que ban hecho de su siglo, reverbera th sus bazares.

leche virginal para que lintos markms se vuelvan verdes, y estulas para que las verde's maduren. El fuego se improvisa con cutleniera de sus novelas. Lágrimas de villrio; curonas paria los vivos y para los muertos, que la vanidád no retrocede ni ante la tumba; lé, en oro de buena ley; amor̀, en opiatas; virlud, en cosméticos; honor, en peleteros; amistad, en bolas de jabon; caridad, en bruñido inármol, $y$ esperanza.... en la misericordia intinita, yue nos sacará de este intierno. Asi encontramos el nundo, y asi lo dejarémos, que es la mentira el alma rle la sociedad, y combalir el error asesinarla.

¿Y á flónde nos llevarí esta larsa? ne preguntarás. A la nada, y conno de ella salimos, labrémos hecho un viage redondo, carillo si se quiere, porcfue hay que perder el corazon, pero divertido. Sacamos en limpio que la vida humana es 11 u bonito vinge, y nosotros muy lélices.... cuando llegamos á tierra, que el mar cuesta muchas lágrimas aunque le llamen $\mathbf{P a -}$ cifico.

NIEGA.

Sabes qua siempre es tu amigo ol angustiado JuAN

yo te doy desde luego gracias por la lisonja, pero elı puntos de conciencia he sido siempre tan severo, yue

F. S. 


\title{
Aivuigta (Gaititalla. \\ rexrosico
}

\section{DE INTERESES MATERIALES, CIENCIAS, LITERATURA, COSTUMBRES}

\author{
Y TRATROS.
}

\section{DIRIJIDO POR D. VICTOR CABALLERO Y VALERO.}

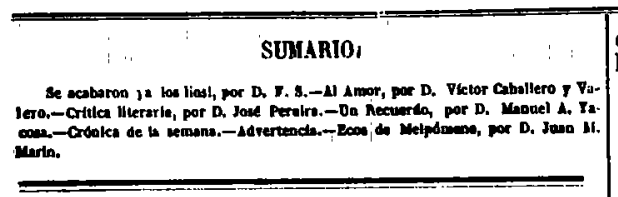

GE'ACABAROK TA IOS LIOS.

Las felicitaciones y parabienes, que diariamente zecibimos de todas las jôvenes; los risueños semblantes y alegres cánticos de los zapateros; la actividad, que se nota en la compra del tabinete, blandurilla y huevos gallegos, y sobre todo el orden y la docilidat con que han entregado las gaditanas las almoliadillas y zarandajas mandadas recojer por el sabio decreto publicailo en el articulo, que con el epigrafo de Tíulos falios, so insertó en el número 10 de esta REvista, han llenado musstro corazou de tal jübilo y satisfaccion, que sin poderlo remediar hemos llorado. Lagrimas de gratilud, lqué lıcrmosas soisl No esperàbamos menos de tan culta poblacion, pero jentín cierto es que en todo apostolado ha de baber un Judasl

En'la nóche del 25, noche de gratos recuerdos para los amintes de las luces, una parte heterogénea del bello sexo, quiso turbar la tranquilidad pública. Ya sospecháhamos nosotros que habian de fraguar alguna trama contra el nuevo órden' de cosns establecido. Creyeron quizá que dormiamos tranquilos sobre nuestros laureles mientras nos minaban ol terreno. Fatal error, que pagaron bien caro..

Si fuésemos militares hariannos la descripcion de la batalla por medio de un parte dotallado, sonoro $y$ campanudo. No hay duda que asi se dá cierto realce á las acciones heróicas, y á las que no lo son, pero jestán ya tán gastados estos recursos! Hay tantos incrédulos! Por otra parte, deseando dar á nuestras bellas un público lestimonio do gratitud y de reconocimiento, creemos que haciendo en un drama la reecña de todo lo ocurrido, lo acogerán favorablemente, recibióndolo como un regalo para las próximas pascuas, y que no podomos dar un botreguito merino á cada uuu como hubiéramos doseado.

bejamos al público el cuidado de juzgar nuestra obra. Nosotros nos limitaremos á decir que es muy buena, pero esto no pasa de una opinion.

GRANDIOSO MELO-UIMO-DRAYA-RISTÓRICO Y MITOLOGICO

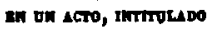

UIN JAQUस⿴囗MATस.

\section{Interlocutores:}

Una encubierta, que se dice Generala de divinion. - Quinientas mujeres que no hablan. Na tondrd nada do particular quo osto sed montira. - Veros.-Cortdo. - Voucano. - Cris

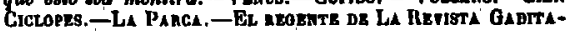

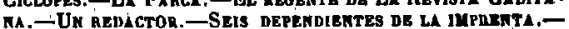

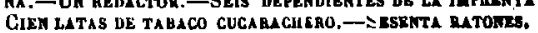

La accion pasa en Cddiz en la noche del 25 de Noviembre de.1867.

\section{ESCENA PRIMERA.}

Alameda, Salon de Cristina.'

Aparecen las quinientas mujeres con tigeras, ascobas y otras armas lodas de fuego como estas. La generala on modlo do allas.

\section{Geneitala.}

Ilustres tabacosas compañeras. El momento del triunfo se acerca. Peliaguda es la obra que traemos entre manos, pero por fortuna teneis á la cabeza una mujer de talento y de valor. Esa soy yo. Muy pronto vereis que no me mamo el dedo.

UNA DE LAS QUINIENTAS (aparte $d$ atis compafieras).

¡Qué pronto se ha llenado de orgullo la muy puercal Generata, (sin oir el requiebro).

El ultrage que hemos recibido reclama una vengan2a sarigrienta.

VARJAs de las qunNignTas (todas a un tiompo, como de costumbre).

-Y pronta, que ya me estoy.durmiendo.

-Y que hace mucho frio.

-Yo estoy temblando. 


\section{TODAS \\ Y yo, y yo, y yo.... \\ Generaha (impasible), \\ Soy jóvel todavla. No cuento mas que cincuenta y cinca años, i pero tengo el aplomo de una mujer de ochenta. Nada temails. Atenclon, quo voy á mandar la maniobra. Echemos á andar juntitas como van los sol- dados. Con que.... Al avío. Yo iré detrás para que nin- guna se vaya. (Aparte) Y para poder correr en çaso necesario. \\ FSCENA SEGUNDA. \\ Imprenta do la Revista Módica. \\ Ajarecen en la escena el regento, ol redactor, los seis dependien. tes. Sobro una mesa las cion latas de tabaco y ent th baul los sesenta ratones. Al frente an tillimo termino una chimenea. \\ Regente.}

Bien le dije å V, que este pegocio ibá tener malas consecuencias.

\section{ReDaCton.}

No: sea V. niño. Todo eso no vale la pena. Esos son los últimos acentas de un quoribundo.

\section{Regente.}

Pues llegan á quinientas las conjuradas, y muy pronto caerán sobre nosotros.

Redactor.

${ }_{b} \mathrm{Y}$ qué nos importan quinientas viejas, cuando hemos salvado á tantas jôvenes? No es posilule gobernar á gusto de todos.

\section{UN DEPENDIENTE.}

IYa llegan, yallegan!

Regente.

ICómo hemos de entendarnos con tantas!

Dependignte.

Lo mejor seria capitular.

Los OTROS CINCO DEPENDIENTES.

Nunca. Primero la muerte que la deshonra.

\section{Redaotor.}

Blen, muy bien; hijps mios, iEspañoles sobre todo! Seamos la segunda edicion de Sagunto y de Numancia nero capitular, jamás. pịspuestos estamos á morir.

REabate (qMarte).

Eso será lo que tase un sastre.

\section{ESCENA TERGERA.}

Dichos y una de las quinientas, quo on edecena.

\section{Eneana.}

Mi Generala desea conferenciar con ustedes antes de meter mano á loos manojos.

Redactor (con ita roepneentrala).

Que venga su señorla.
Aquí está ya.

Enfcana.

ESCENA CUAR'TA,

Dichos y la Ganerula.

Genemala.

Quisięra ver á cualquiera de los redactores.

Renacton.

Puedo V. decir lo que guste. Soy uno de ellos.

\section{Generala.}

En ese caso, bpodrá decirme quiénl es el que ha declarado guerra á rnuerte al bello sexo?

\section{REDACTON.}

¡Guerra al sexo bello! ninguno, șñora. Ninguno.

Generata.

¿Con que no, eh? ¿Y ese bando? ¿Y esa proclama? El infierno entero se ha desitado contra nosolras.

REGENTE (aparle).

No lo sabes th muy bien.

\section{Ríedacion.}

Tranquilícese V., señora. Esa proclama y ese bando léjos de perjudicar á nuestras hermosas, las prepara un halagüeño porvenir.

\section{GENEHALA.}

Sí, sí, muy halagũeño. Han arruinado Vds. á las tres cuartas partes de la poljlacion, pero este crimen no quedará sin castigo. $A$ eso venimos.

REDAC'TOR.

¿Y quá se ęxige de nosotros?

Generala.

La derogacion de la ley, que nos arruina.

EL REGENTE Y LOS SEIS DEPENDIENTES.

Jamás, jamás (Cantando en tono de dómenor). Si quereis sangre, sangre tendremos...

\section{Generala.}

Ese tóno tiene tres bemoles, JVan á cantarme el trágala, señor redactor!

REDACTOR.

Callaḍ ya, ruiseñores. La señoja Generala ng eștá ahora para músicas.

\section{GAENERALA}

Dice V. muy bien. Tengo la cabeza como una olla de grillos, pero cuidado quo esta no es grilla. Noy a oxplícarme sin rodeos, Quisiera que estuviósomos solos. (A una seña del redactor se colocan an wiltimo término formando un semiciroulo, la edeeana, ol nepentu y los seis dopendientes. La edecana proourayd no perder ni una *illaba de cuanto se hable. E\& mujer. Fa'lo hamos dicho antes). 


\section{Genenala (con muoho misterio). \\ Que yo soy una señora lo están diclendo mi trage y mis finos modales, y que no soy un saco do paja ala vista esth́. (Puedo mentir a su gusto porque no habrd mas luz que la de un candil, que deberd estar tan mustio y tristo como un cesante.)}

Genenala (continuando au elocuentediscurso),

Pues bien, si el ejército que me stgie y yo dishrutamos todnvin de la reputación de bellas, al arte os a quien debemos esta dicha. Soy franca, señor redactor Almas en pena parecemos a las ocho de la mañana pero diez o doce horns de tocador hacen una transformacion admirable. Este color sonrosado, estos dientes, que parecen piitones, $\mathrm{mi}$ preciosa y torneada trastienda del vientre, todo, todo es obra'slel arte. Mi hermosa cabellera es un recuerdo de amistad. Otra cabeza so adornó con ella.

\section{Rènactor}

Su nombre de V., señora, su nombre. (Aparte.) ¿Si será Satanásl

\section{Generala.}

Mi nombre no hace al caso, pero para que se convenzan de que es la verdad pura cuonto lo he dicho, allá vá mi retaguardia. (Suelta dos cintas y deja caer una albarda de algodon forrada en miriñaque.)

$$
\text { RFDacton (admirado.) }
$$

¡Nucha trastienda liene V., nit Generalal

\section{Generula.}

Regular, regular. Cinco arrobas escasas. Ahora yéame V. sin peluca. (Mientras se la quita, uno de los dependientes echa aceite al candil.)

\section{REDACTOR.}

¡Jesus mil veces! ¿Qué fea es mi Generala! Generala (con dignidad.)

Ya yo lo sabia. Hace 55 años que me dieron esa noticia.

REDactor (dandose una palmada en la frente.)

Pero V. es. sí, sí.... no me engâno. V.es la ocasion. Compañeros, 'á ella. A la Ocasion la pintan calva. La señora Generala es la Ocasion.

\section{Generala (furiosa.)}

Me han reconocido. ¿Por qué me quitaria yo la peluca? (Dirijiéndose a la tropu que avanza). Atrás, infames. Reparen Vds. que soy la suegra de....

\section{Penactor (echando babas de corago.)}

¡Es una suegra! ¡Quó horror! Siempre han de perseguirme estos avichuchos. V. debemorir, señora, $V$. debe mbitir, no hay remedio, QQuién le ha dicho que las suegras pertenecen al bello sexo? ¿No han engañado ya bastante? Antropofagos, ¿quieren Vils todavia mas victimas? Pues no, no las habiá, Dí mico, que no te darán en el pico. Compañeros, á las armas. Vira el bello sero.

Viva.

\section{Redactor.}

Mueran las suegrat.

\section{Mueran.}

$$
\text { Tonos (menos los dolientes) }
$$

Al ver la edecana que la cosa se váponii ndo fea sale á llamar á sus compañeras. Ja Generala saca unas tigeras y una daguilla de hacér calcetas. Las quinientas mujeres aparecen por el foro. Trábase ol combate. Los muchnchos de, la imprenta empiezan a repartir las latas de tabaco, Aquel ejercito olvida la disciplina y se deja sobornary En el calor de la refriega el regente de la imprenta dá larta á lós sesenta ratones. Entra la dispersion. La Generala que lo observa, quiere sui-' cidarse, pero en vez de darsé el golpe con las tigeras, se lo da con la daguilla, y empieza á echar libras de algodon en rama por el pecho. Asoma Cupido por las bambalinas á dar parte de que viene á la fiesta su mamá. Efectivamente, al poco rato aparece entre nubes Venus, con mantilla de tiras, saya de cachucha. y zapatos de tabinete. El redactor de la Revista Ga ditana se pone tan huecco al ver que hasta el Empireo ha aprobado la reforma. A una voz dé Venus salen de la chimenea Vulcano y los cien clclopes para recojer todos los prisioneros. Una clara luz ifumina la escena y en último término aparece la Muerte con la guadaña levantada en ademan de dar MULE. Todas estas escenas han de ser muy rápidas. Venus desde su trono de nubes, dice á las facciosas:

Viejas infames, de morir es Hora, Orgullo y prestincion lá Parca abato, $\mathrm{Y}$ al levantar su diestra vengadora Vá á daros sin remedio JAQUE MATE.

La Generala tararea la plegaria de la Norma «Casta Diva.s Las quinientas' hacen el coro con llanto, convulsiones, congojas y ataques de nervios. Empieza la matanza, y cae el telon ocultando un espectáculo tan. horroroso. El público llorará como viuda rica, es decir, muy poquito, pero convencido de que en circuinstancias criticas hay que adoptar medidas extraordinarias, gritará entusiasmado. Es verdad que ha habido victimas, pero

SE ACABARON YA LOS LIOS.

F. S.

A.I AMOE.

ROMANOE DE OPOSICION FURIOSA.

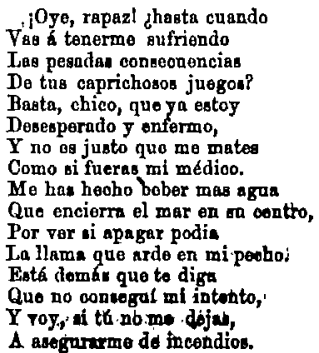

†Oye, rapaz! dhasta cuando

Thesporado y enfermo,

Como si fueras mi médioo.

Me has hooho bober mas agan

Que encierro el mar on ta oentto.

Por ver ii apagar podís

La llama que ardo en mi ponbo

dereng qu diga

Y roy, a th.no.me dojw,

$\triangle$ aseginarme de incendios. 